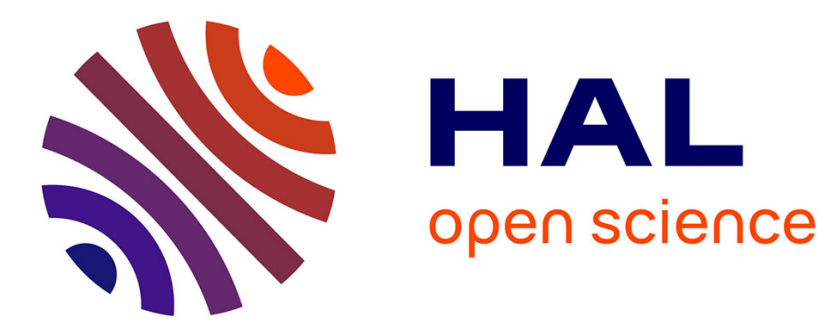

\title{
Does occurrence during sports affect sudden cardiac arrest survival?
}

\author{
Louis Pechmajou, Ardalan Sharifzadehgan, Wulfran Bougouin, Florence \\ Dumas, Frankie Beganton, Daniel Jost, Lionel Lamhaut, Eric Lecarpentier, \\ Thomas Loeb, Frédéric Adnet, et al.
}

\section{To cite this version:}

Louis Pechmajou, Ardalan Sharifzadehgan, Wulfran Bougouin, Florence Dumas, Frankie Beganton, et al.. Does occurrence during sports affect sudden cardiac arrest survival?. Resuscitation, 2019, 141, pp.121 - 127. 10.1016/j.resuscitation.2019.06.277 . hal-03486869

\section{HAL Id: hal-03486869 \\ https://hal.science/hal-03486869}

Submitted on 20 Dec 2021

HAL is a multi-disciplinary open access archive for the deposit and dissemination of scientific research documents, whether they are published or not. The documents may come from teaching and research institutions in France or abroad, or from public or private research centers.
L'archive ouverte pluridisciplinaire HAL, est destinée au dépôt et à la diffusion de documents scientifiques de niveau recherche, publiés ou non, émanant des établissements d'enseignement et de recherche français ou étrangers, des laboratoires publics ou privés.

\section{다)(1) $(5$}

Distributed under a Creative Commons Attribution - NonCommerciall 4.0 International 


\section{Does Occurrence during Sports affect Sudden Cardiac Arrest Survival? Short Title: Survival in Sports-Related Sudden Cardiac Arrest}

Louis Pechmajou, MD, MPH ${ }^{1,2,3}$; Ardalan Sharifzadehgan, MD, MPH ${ }^{1,2,3}$; Wulfran Bougouin, MD, $\mathrm{PhD}^{1,2,3}$; Florence Dumas, MD, $\mathrm{PhD}^{1,2,4}$; Frankie Beganton, $\mathrm{MS}^{1}$; Daniel Jost, $\mathrm{MD}^{6}$; Lionel Lamhaut, MD, $\mathrm{PhD}^{2,7}$; Eric Lecarpentier, $\mathrm{MD}^{8}$; Thomas Loeb, $\mathrm{MD}^{9}$; Frédéric Adnet $\mathrm{MD}, \mathrm{PhD}^{10}$; Jean-Marc Agostinucci $\mathrm{MD}^{10}$; Kumar Narayanan, $\mathrm{MD}^{11}$; Georgios Sideris, $\mathrm{MD}^{12}$, Sebastian Voicu, MD, ${ }^{13}$ Alain Cariou, MD, $\mathrm{PhD}^{1,2,14}$; Christian Spaulding, MD, $\mathrm{PhD}^{1,2,3}$; Eloi Marijon, MD, $\mathrm{PhD}^{1,2,3}$; Xavier Jouven, $\mathrm{MD}, \mathrm{PhD}^{1,2,3^{*}}$; Nicole Karam, MD, $\mathrm{PhD}^{1,2,3^{*}}$, On Behalf of the Paris-Sudden Death Expertise Center (Paris-SDEC) Investigators

\section{*Equally contributed}

${ }^{1}$ Paris-Sudden Death Expertise Center (Paris-SDEC), INSERM Unit 970, Paris Cardiovascular Research Center, Paris, France

${ }^{2}$ Paris Descartes University, Paris, France

${ }^{3}$ Cardiology Department, European Hospital Georges Pompidou, Paris, France

${ }^{4}$ Emergency Department, Cochin Hospital, Paris, France

${ }^{6}$ Paris Firefighters Brigade, Paris, France

${ }^{7}$ Emergency Medical Services (SAMU) 75, Necker Hospital, Paris, France

${ }^{8}$ Emergency Medical Services (SAMU) 94, Henri Mondor Hospital, Creteil, France

${ }^{9}$ Emergency Medical Services (SAMU) 92, Raymond Poincaré Hospital, Garches, France

${ }^{10}$ Emergency Medical Services (SAMU) 93, Avicenne Hospital, Bobigny, France

${ }^{11}$ Cardiology Department, Maxcure Hospital, Hyderabad, India

${ }^{12}$ Cardiology Department, Lariboisiere Hospital, Paris, France

${ }^{13}$ Intensive Care Unit, Lariboisiere Hospital, Paris, France

${ }^{14}$ Intensive Care Unit, Cochin Hospital, Paris, France

\section{Corresponding author:}

Nicole Karam, MD, PhD

European Hospital Georges Pompidou

Cardiology Department and Cardiovascular Epidemiology Unit (INSERM Unit 970)

20-40 Rue Leblanc, 75908 Paris Cedex 15, France

Phone: +33156093614

Email: nicole.karam@aphp.fr

\section{Conflict of interest: None}

Word count: 2373 


\begin{abstract}
Word count 249)
Objectives: A higher survival rate was observed in Sudden Cardiac Arrest (SCA) occurring during sports activities, although the underlying mechanisms remain unclear. We tested the hypothesis that better initial management, rather than sports per se, may account for the observed better outcomes during sports activities.

Methods: Data was taken between May 2011 and March 2016 from a prospective ongoing registry that includes all SCA in Paris and suburbs (6.7 million inhabitants). Sports-related SCA (i.e. SCA occurring during sport activities or within one hour of cessation of the activity) were identified.

Results: Over the study period, 13,400 SCA occurred, of which 154 were sports-related (median age: 51.2 years, $96.1 \%$ males). At discharge, sports activity was associated with an 8-times higher survival rate (39.7\% vs. 5.1\%, $\mathrm{P}<0.001)$. Logistic regression showed that after considering potential confounders, including age, gender, SCA location, witness presence, time to response, and initial shockable rhythm, occurrence of SCA during sports was associated with a higher survival rate (OR 1.77, 95\% CI 1.14-2.74, P=0.01). However, after further adjustment for initial basic life support, i.e. bystander CPR and AED use, there was no association between sports setting and survival at hospital discharge (OR 1.43, 95\% CI 0.91-2.23, $\mathrm{P}=0.12$ )

Conclusion: Sports-related SCA is a rare event, with an 8-times higher survival rate compared to non-sportsrelated SCA. Better initial management, including bystander CPR and AED use, rather than sports per se, mainly accounts this difference. This highlights the major importance of population education to basic life support in improving SCA outcome.
\end{abstract}

Keywords: Sudden death; Exercise; Screening; Prevention; Education 


\author{
79 Abbreviations list \\ 80 SCA: Sudden Cardiac Arrest \\ 81 SDEC: Sudden Death Expertise Centre \\ 82 CCPPRB: Committee for the Protection of Human Subjects in Biomedical Research \\ 83 CNIL: Commission Nationale Informatique et Liberté \\ 84 EMS: Emergency Medical Service \\ 85 AED: Automated External Defibrillation \\ 86 ECG: electrocardiogram \\ 87 ROSC: return of spontaneous circulation \\ 88 ECMO: Extra-Corporeal Membrane Oxygenation \\ 89 CPC: Cerebral Performance Category \\ 90 STROBE: Strengthening the Reporting of Observational Studies in Epidemiology
}




\section{INTRODUCTION}

Despite the well-documented benefits of regular sport activity on the reduction of cardiovascular events,[1] the risk of Sudden Cardiac Arrest (SCA) is transiently increased during or shortly after exercise, a concept that is known as the exercise paradox.[2-4] Sports-related SCA have traditionally been associated with young competitive athletes due to the high media coverage and emotional impact of SCA occurring during competition, in a population that is commonly considered as healthy and fit.[5,6] However, more recent studies have shown that sports-related SCA occur more frequently among recreational athletes, especially among middle age participants, with an estimated number of 8000-10000 cases each year in Europe and approximately half this number in the United States.[7-10]

Beyond the issue of incidence in different subgroups of sport participants, the impact of occurrence during sports on SCA prognosis has not been well investigated. Several studies have shown a higher crude survival rate of sports-related SCA compared to non-sports related SCA. $[8,11,12]$ In which extent this better outcome is related to participants' characteristics and to exercise per se, rather than to external factors associated to the specific setting of sports practice has not been fully evaluated.

Using data from a large prospective community-based study in the Paris area, carried out in the general population, we tested the hypotheses that a better initial management, rather than sports per se, may account for the observed better outcomes during sports activities. 


\section{METHODS}

\section{Study Population and Setting}

The Paris-Sudden Death Expertise Centre (SDEC) registry was initiated in May 15, 2011.[13-15] It includes all SCA occurring in Paris and its suburbs, which accounts for a residential population of approximately 6.7 million (10\% of the overall French population). This prospective study is conducted according to the Declaration of Helsinki, with the approval of the Committee for the Protection of Human Subjects in Biomedical Research (CCPPRB) and the French data protection committee (Commission Nationale Informatique et Liberté, CNIL).

In the Paris area, the Emergency Medical Service (EMS) is a two-tiered response system: a Basic Life Support tier served by fire-fighters of the Brigade de Sapeurs Pompiers de Paris, who can apply Automated External Defibrillation (AED), and an advanced cardiac life support tier served by ambulance teams with an emergency physician, a nurse, and/or a paramedic (Service d'Aide Médicale Urgente). For every SCA assessed by EMS, each of the EMS tiers sends a nominative report form to the SDEC (source 1). To ensure completeness, an electronic query algorithm is also performed in the advanced cardiac life support computer system to identify every case of SCA (source 2). Finally, regular controls based on diagnostic codes are conducted in selected intensive care units (control). With this meticulous data collection and verification, the exhaustiveness of the database was estimated to be $98.6 \%$.[16]

Sports-related SCA was defined as SCA occurring during sport activities or within one hour of cessation of the activity. Sports-related sudden deaths related to trauma (for example, runner or cyclist hit by a car) were excluded. [17][18] Sports facilities were defined as activities practiced (i) in places specially designed, regardless of their size (including stadium, tennis facilities, etc), or (ii) in the context of competition. By contrast, setting was defined as outside of sports facilities for others-individuals who performed sports activities without any structure or organized competition.[19]

\section{Collected Utstein Data}

Data are collected according to the Utstein recommendations.[20] Exclusion criteria were patient's age of less than 18 years, SCA occurring outside the area of interest, prior terminal condition (such as metastatic malignancy), or obvious non-medical cause according to Utstein templates (traumatic, drug overdose, drowning, asphyxia...). Collected data include general information regarding demographic characteristics, past medical history, basic life 
support (cardiopulmonary resuscitation (CPR) and AED use), initial cardiac rhythm, electrocardiogram (ECG) characteristics when return of spontaneous circulation (ROSC) is obtained, use of Extra-Corporeal Membrane Oxygenation (ECMO), targeted temperature control, coronary angiography and angioplasty. Survival and neurological status (according to Cerebral Performance Category (CPC) score, considering a CPC score of 1 or 2 as a favorable outcome) at hospital admission and discharge are also recorded. At least two independent reviewers determine the causes of SCA after analyzing each file. They also systematically review each record in order to guarantee data completion and validity.

\section{Statistical Analysis}

145 This report was prepared in compliance with the STROBE (Strengthening the Reporting of Observational Studies 146 in Epidemiology) checklist for observational studies.[21] Variables were reported as mean, SD, proportion, median 147 and interquartile range, as appropriate. Comparisons between groups (sports versus non-sports-related) were performed using the $\chi^{2}$ test or the Fisher exact test for categorical variables, and the Student $\mathrm{t}$ test or MannWhitney test for continuous variables, as appropriate. Logistic regression models were used to estimate the odds ratios (OR) and their 95\% confidence interval (95\% CI) for the association between the time of SCA occurrence and the odds of being alive at hospital discharge. A univariate analysis was first performed with all the descriptive variables, and the association between these variables and the survival rate was tested using the Wald test. Multivariate analysis was performed with adjustment for all the variables that were significant in the univariate analysis. All tests were two-tailed, and $P$ values of less than 0.05 were considered to indicate statistical significance. All data were analyzed at the Sudden Death Expertise Centre, INSERM, Unit 970, Paris, using R software, version 3.3.1. The authors had full access to data and designed the statistical analysis, had final responsibility for the decision to submit the manuscript for publication, and vouch for the accuracy and completeness of the data and the analyses. 


\section{RESULTS}

\section{Characteristics of SCA occurring during sport activities}

Between May 2011 and March 2016, 18,306 out-of-hospital cardiac arrests were recorded. Of those, 2,655 patients had obvious non-medical causes and 435 patients had a prior terminal condition. Therefore, 15,216 SCA were identified. After excluding 1,816 patients aged over 90, 13,400 patients were included in the study; 154 occurred during sports activities (Figure 1).

Baseline characteristics of SCA, according to the occurrence during sports activities, are described in Table 1. Sports-related SCA victims were younger (median age: 51.2 [40.8-60.7] vs. 69.8 [57.0-81.4] years in the non-sports population, $P<0.001)$, with a higher proportion of males $(96.1 \%$ vs. $64.1 \%, P<0.001)$. Sports-related SCA occurred mainly during running (59 cases, 38.3\%), cycling (21 cases, 13.6\%), football (15 cases, 9.7\%) and fitness activities (13 cases, 8.4\%; Supplementary Figure), with 43.8\% (49 cases) occurring in public sports facilities.

\section{Initial management and Basic Life Support}

Compared to non-sports related SCA, sports-related SCA occurred more frequently in a public location $(90.9 \%$ vs. $20.3 \%, P<0.001)$. Witnesses were more often present $(95.4 \%$ vs. $70.7 \%, P<0.001)$, and were more likely to initiate CPR (82.9\% vs. $54.5 \%, P<0.001)$, and to use AEDs prior to EMS arrival (15.3\% vs. $2.3 \%, P<0.001$ ), compared to non-sports related SCA. Bystander' CPR was performed in 121 cases $(79.1 \%)$ in the sports-related SCA group vs. 4,639 cases $(38.6 \%)$ in the non-sports related SCA group $(P<0.001)$, with an AED used in 21 cases $(14.7 \%)$ of sports-related SCA vs. 130 cases $(1.4 \%)$ of non-sports related SCA $(P<0.001)$.

In the particular case of SCA occurring in sports complex, 47 cases (95.9\%) were witnessed. Bystander CPR was performed in 43 cases (87.8\%), with an AED used in 12 cases (25.5\%). Outside sports complexes, when comparing all SCA occurring in public areas, the rate of bystander CPR (83.6\% vs. $64.3 \%, \mathrm{P}<0.001)$, and AED use (15.6\% vs. $6.5 \%, \mathrm{P}<0.001)$ were still higher during sports activities.

\section{Advanced medical resuscitation}

The proportion of EMS-witnessed SCA $(10.8 \%$ vs. $11.5 \%, P=0.89)$ and of time delay < 9 min between the call-toEMS and EMS arrival did not differ between the two groups (39.6\% vs. $41.9 \%, P=0.63)$. The rate of shockable 
initial rhythm was higher during sports activities $(77.8 \%$ vs. $20.2 \%, P<0.001)$, and ECMO was more frequently used $(14.9 \%$ vs. $2.6 \%, P<0.001)$.

ROSC was more frequently obtained in sports-related SCA $(62.9 \%$ vs. $29.4 \%, P<0.001)$, and the survival rate at hospital admission was higher $(79.7 \%$ vs. $23.3 \%, P<0.001)$. Among survivors to hospital admission, there was no significant difference in the rates of targeted temperature control $(53.6 \%$ vs. $53.3 \%, P=0.77)$ and coronary angiography $(70.9 \%$ vs. $61.0 \%, P=0.20)$ (Table 1$)$.

\section{Presumed cause of SCA and past medical history}

Sports-related SCA patients were less likely to have a prior history of heart disease $(16.5 \%$ vs. $33.9 \%, \mathrm{P}=0.014)$ and coronary artery disease $(7.0 \%$ vs. $18.9 \%, \mathrm{P}=0.015)$. In terms of cardiovascular risk factors, sports-related SCA were less frequently active smokers $(19.6 \%$ vs. $34.2 \%, \mathrm{P}<0.001)$ and diabetics $(5.6 \%$ vs. $21.0 \%, \mathrm{P}=0.006)$. There was no difference in the rates of dyslipidemia and hypertension between the 2 groups.

Among patients who survived at hospital admission, the cause of SCA could be identified in 89 (75.4\%) sportsrelated SCA and 1,949 (72.1\%) non-sports-related SCA $(P=0.49)$. When the SCA etiology was found, a cardiac cause was more frequently identified in the sports-related SCA group $(94.4$ vs. $63.7, P<0.001)$. CAD was the most frequent cause of SCA in the global SCA population, with a higher prevalence in sports compared to non-sports related SCA (66.3\% vs. 50.4\%, $P=0.003)$ (Figure 2).

\section{Survival influencing factors}

Sports-related SCA had a better survival rate at hospital discharge $(39.7 \%$ vs. $5.1 \%, P<0.001)$ with a similar rate of CPC score 1 or 2 at discharge among survivors (94.2\% vs. $94.8 \%, P=0.986)$, compared to non-sports related SCA.

On univariate analysis, shockable initial rhythm was the strongest survival predictor (OR 29.43, 95\% CI 23.82-36.72, $P<0.001$ ), followed by bystander CPR (OR 16.48, 95\% CI 11.54-24.55, $P<0.001$ ) and occurrence during sports (OR 12.22, 95\% CI 8.66-17.13, $P<0.001)$ (Table 2).

After adjustment for age, gender, SCA location, call to EMS arrival $<9 \mathrm{~min}$, and initial shockable rhythm, occurrence during sports was associated with a higher survival rate $(1.6695 \% \mathrm{CI} 1.08-2.54, P=0.025)$. However, after adjustment for witnessed status, i.e. bystander CPR and witness presence, there was no association between occurrence of SCA during sports activity and survival at hospital discharge (OR 1.41, 95\% CI 0.91-2.17, 
$211 P=0.122$ ) (Table 3). Occurrence during was not associated neither with survival with a better neurological outcome 212 (OR 1.40, 95\% CI 0.89-2.19, $P=0.14)$.

213

214

215 


\section{DISCUSSION} In this prospective and extensive collection of all cases of SCA occurring in Paris and its suburbs over a five-year period, sports-related SCA occurred mainly in middle-aged men. Survival rate at hospital discharge was 7 to 8 times higher in sports-related SCA, despite a very similar in-hospital medical management. Higher rates of bystander' CPR and AED use in sports-related SCA appear to account for this higher survival rate, whereas sports activity per se was not associated to a better outcome, illustrating the major yield of bystanders in improving SCA prognosis.

There is conflicting evidence regarding the impact of sport occurrence on the survival after SCA. Whereas most studies in the general population have reported a higher survival rate in sports-related SCA, the exact role occurrence during sports in this better prognosis remains unclear.[11,22] Several hypotheses have been made, linking the better outcome to a cardioprotective role of sports on the endothelium and vascular function, as well as to the higher activation of the sympathetic system during sports.[11] Other hypotheses focused on the better management of sports-related SCA that could also be playing a role in this better survival rate.[19]

Although we observed a dramatically higher rate of survival when SCA occurs during sports, after adjustment for the main known prognostic factors, exercise per se was not associated to a better survival rate. EMS arrival delays and in-hospital management could not account for this improved survival neither since they did not differ according to whether SCA occurred during sports or not. Besides, we previously demonstrated that differences in the characteristics of accepting hospital did not influence SCA outcome in Paris and its suburbs.[23] Conversely, we observed differences in bystanders' response to SCA, with a higher rate of bystander CPR and AED use in sports-related SCA, even when considered only witnessed SCA occurring in public areas.

Our results illustrate the major impact of the early phase of SCA management, and the paramount role of bystanders in improving SCA prognosis. This finding has been previously demonstrated in the context of sportsrelated SCA through a French national study, where major heterogeneities have been observed among districts in terms of survival after sports-related SCA, mainly due to differences in the rate of bystander-initiated CPR.[24] Efforts should be made to improve bystanders CPR and AED use rate in all-comers SCA where the rate of CPR and AED remains low, leading to a much lower survival rate than in the sports setting.[25] 
Efforts for reducing sports-related SCA burden have focused on the identification of athlete who are at risk of SCA. Most studies on sports-related SCA have focused on young competitive athletes and the priority has been given to pre-participation screening in competitive sport. [5,26-28] However, in our study, most sportsrelated SCA cases occurred in middle-aged leisure athletes, among whom the identification of participants at risk of SCA is more difficult. European Guidelines recommended a clinical evaluation, including exercise testing may be considered for sedentary people with cardio-vascular risk factors who intend to engage in vigorous physical activity.[29] The efficiency of this strategy in reducing the incidence of sports-related SCA has not been demonstrated, and SCA-risk assessment among athletes have been challenging. Given the difficulty in reducing the incidence of sports-related SCA, more efforts should focus on implementing measures to improve SCA survival rate once it occurred, mainly by population education to basic life support. Besides bystanders' education, education of sports participants could possibly reduce the incidence of SCA. In a previous study, we observed that most patients with sports-related SCAs presented warning symptoms before SCA, but maintained their physical activity anyway.[14] Educating the participants to recognize warning symptoms and seek medical advice before SCA could help avoiding several cases of SCA.

Several limitations have to be acknowledged, first, due to the very low rate of systematic autopsy in France, the cause of OHCA could not be established in all cases. Second, information regarding the degree of physical activity on a daily basis was not available in the database and causality between SCA and sports activity could be debated in cases where the level of physical exercise was low. Finally, this study was conducted in Paris and its suburbs. The extent to which similar results could be obtained in countries with a different health care system needs further evaluations.

In conclusion, sports-related SCA is a rare event with a much better prognosis than SCA during at rest or during other activities. Better initial management, including higher rates of bystander CPR and AED use, rather than sports per se, account for this difference. This observation highlights the major impact of bystanders' basic life support in improving SCA survival, and the need to extend population education to basic life support. 
[1] Paffenbarger RS, Hyde RT, Wing AL, Lee IM, Jung DL, Kampert JB. The association of changes in physical-activity level and other lifestyle characteristics with mortality among men. N Engl J Med 1993;328:538-45. doi:10.1056/NEJM199302253280804.

[2] Deo R, Albert CM. Epidemiology and Genetics of Sudden Cardiac Death. Circulation 2012;125:620-37. doi:10.1161/CIRCULATIONAHA.111.023838.

[3] Siscovick DS, Weiss NS, Fletcher RH, Lasky T. The incidence of primary cardiac arrest during vigorous exercise. N Engl J Med 1984;311:874-7. doi:10.1056/NEJM198410043111402.

[4] Albert CM, Mittleman MA, Chae CU, Lee IM, Hennekens CH, Manson JE. Triggering of sudden death from cardiac causes by vigorous exertion. N Engl J Med 2000;343:1355-61. doi:10.1056/NEJM200011093431902.

[5] Maron BJ, Doerer JJ, Haas TS, Tierney DM, Mueller FO. Sudden deaths in young competitive athletes: analysis of 1866 deaths in the United States, 1980-2006. Circulation 2009;119:1085-92. doi:10.1161/CIRCULATIONAHA.108.804617.

[6] Corrado D, Pelliccia A, Bjørnstad HH, Vanhees L, Biffi A, Borjesson M, et al.

Cardiovascular pre-participation screening of young competitive athletes for prevention of sudden death: proposal for a common European protocol. Consensus Statement of the Study Group of Sport Cardiology of the Working Group of Cardiac Rehabilitation and Exercise Physiology and the Working Group of Myocardial and Pericardial Diseases of the European Society of Cardiology. Eur Heart J 2005;26:516-24. doi:10.1093/eurheartj/ehi108.

[7] Marijon E, Tafflet M, Celermajer D, Dumas F, Perier M, Mustafic H, et al. Sports-related sudden death in the general population. Circulation 2011;124:672-81. doi:10.1161/CIRCULATIONAHA.110.008979.

[8] Marijon E, Uy-Evanado A, Reinier K, Teodorescu C, Narayanan K, Jouven X, et al. Sudden cardiac arrest during sports activity in middle age. Circulation 2015;131:1384-91. doi:10.1161/CIRCULATIONAHA.114.011988.

[9] Mohananey D, Masri A, Desai RM, Dalal S, Phelan D, Kanj M, et al. Global Incidence of Sports-Related Sudden Cardiac Death. J Am Coll Cardiol 2017;69:2672-3. doi:10.1016/j.jacc.2017.03.564.

[10] Cheah SO, Ong MEH, Chuah MBF. An eight year review of exercise-related cardiac arrests. Ann Acad Med Singapore 2010;39:542-6.

[11] Berdowski J, de Beus MF, Blom M, Bardai A, Bots ML, Doevendans PA, et al. Exerciserelated out-of-hospital cardiac arrest in the general population: incidence and prognosis. Eur Heart J 2013;34:3616-23. doi:10.1093/eurheartj/eht401. 
[12] Torell MF, Strömsöe A, Zagerholm E, Herlitz J, Claesson A, Svensson L, et al. Higher survival rates in exercise-related out-of-hospital cardiac arrests, compared to non-exerciserelated - a study from the Swedish Register of Cardiopulmonary Resuscitation. Eur J Prev Cardiol 2017:2047487317729251. doi:10.1177/2047487317729251.

[13] Bougouin W, Lamhaut L, Marijon E, Jost D, Dumas F, Deye N, et al. Characteristics and prognosis of sudden cardiac death in Greater Paris: population-based approach from the Paris Sudden Death Expertise Center (Paris-SDEC). Intensive Care Med 2014;40:846-54. doi:10.1007/s00134-014-3252-5.

[14] Karam N, Pechmajou L, Dumas F, Bougouin W, Sharifzadehgan A, Beganton F, et al. Comprehensive Assessment of Coronary Artery Disease in Sports-Related Sudden Cardiac Arrest. Circulation 2018. doi:10.1161/CIRCULATIONAHA.118.034664.

[15] Jabre P, Bougouin W, Dumas F, Carli P, Antoine C, Jacob L, et al. Early Identification of Patients With Out-of-Hospital Cardiac Arrest With No Chance of Survival and Consideration for Organ Donation. Ann Intern Med 2016;165:770-8. doi:10.7326/M16-0402.

[16] Karam N, Marijon E, Dumas F, Offredo L, Beganton F, Bougouin W, et al. Characteristics and outcomes of out-of-hospital sudden cardiac arrest according to the time of occurrence. Resuscitation 2017;116:16-21. doi:10.1016/j.resuscitation.2017.04.024.

[17] Marijon E, Bougouin W, Périer M, Celermajer D, Jouven X. Incidence of sports-related sudden death in France by specific sports and sex. JAMA 2013;310:642-3. doi:10.1001/jama.2013.8711.

[18] Marijon E, Bougouin W, Celermajer DS, Périer M-C, Dumas F, Benameur N, et al. Characteristics and Outcomes of Sudden Cardiac Arrest During Sports in Women. Circ Arrhythm Electrophysiol 2013;6:1185-91. doi:10.1161/CIRCEP.113.000651.

[19] Marijon E, Bougouin W, Karam N, Beganton F, Lamhaut L, Perier M, et al. Survival from sports-related sudden cardiac arrest: In sports facilities versus outside of sports facilities. Am Heart J 2015;170:339-345.e1. doi:10.1016/j.ahj.2015.03.022.

[20] Perkins GD, Jacobs IG, Nadkarni VM, Berg RA, Bhanji F, Biarent D, et al. Cardiac arrest and cardiopulmonary resuscitation outcome reports: update of the Utstein Resuscitation Registry Templates for Out-of-Hospital Cardiac Arrest: a statement for healthcare professionals from a task force of the International Liaison Committee on Resuscitation (American Heart Association, European Resuscitation Council, Australian and New Zealand Council on Resuscitation, Heart and Stroke Foundation of Canada, InterAmerican Heart Foundation, Resuscitation Council of Southern Africa, Resuscitation Council of Asia); and the American Heart Association Emergency Cardiovascular Care Committee and the Council on Cardiopulmonary, Critical Care, Perioperative and Resuscitation. Circulation 2015;132:1286- 
300. doi:10.1161/CIR.0000000000000144.

[21] Vandenbroucke JP. The making of STROBE. Epidemiol Camb Mass 2007;18:797-9. doi:10.1097/EDE.0b013e318157725d.

[22] Søholm H, Kjaergaard J, Thomsen JH, Bro-Jeppesen J, Lippert FK, Køber L, et al. Myocardial infarction is a frequent cause of exercise-related resuscitated out-of-hospital cardiac arrest in a general non-athletic population. Resuscitation 2014;85:1612-8. doi:10.1016/j.resuscitation.2014.06.033.

[23] Chocron R, Bougouin W, Beganton F, Juvin P, Loeb T, Adnet F, et al. Are characteristics of hospitals associated with outcome after cardiac arrest? Insights from the Great Paris registry. Resuscitation 2017;118:63-9. doi:10.1016/j.resuscitation.2017.06.019.

[24] Marijon E, Bougouin W, Celermajer DS, Perier M-C, Benameur N, Lamhaut L, et al. Major regional disparities in outcomes after sudden cardiac arrest during sports. Eur Heart J 2013;34:3632-40. doi:10.1093/eurheartj/eht282.

[25] Page RL, Husain S, White LY, Rea TD, Fahrenbruch C, Yin L, et al. Cardiac arrest at exercise facilities: implications for placement of automated external defibrillators. J Am Coll Cardiol 2013;62:2102-9. doi:10.1016/j.jacc.2013.06.048.

[26] Drezner JA, Peterson DF, Siebert DM, Thomas LC, Lopez-Anderson M, Suchsland MZ, et al. Survival After Exercise-Related Sudden Cardiac Arrest in Young Athletes: Can We Do Better? Sports Health 2018:1941738118799084. doi:10.1177/1941738118799084.

[27] Harmon KG, Asif IM, Maleszewski JJ, Owens DS, Prutkin JM, Salerno JC, et al. Incidence, Cause, and Comparative Frequency of Sudden Cardiac Death in National Collegiate Athletic Association Athletes: A Decade in Review. Circulation 2015;132:10-9. doi:10.1161/CIRCULATIONAHA.115.015431.

[28] Maron BJ, Levine BD, Washington RL, Baggish AL, Kovacs RJ, Maron MS. Eligibility and Disqualification Recommendations for Competitive Athletes With Cardiovascular Abnormalities: Task Force 2: Preparticipation Screening for Cardiovascular Disease in Competitive Athletes: A Scientific Statement From the American Heart Association and American College of Cardiology. J Am Coll Cardiol 2015;66:2356-61. doi:10.1016/j.jacc.2015.09.034.

[29] Piepoli MF, Hoes AW, Agewall S, Albus C, Brotons C, Catapano AL, et al. 2016 European Guidelines on cardiovascular disease prevention in clinical practice: The Sixth Joint Task Force of the European Society of Cardiology and Other Societies on Cardiovascular Disease Prevention in Clinical Practice (constituted by representatives of 10 societies and by invited experts)Developed with the special contribution of the European Association for Cardiovascular Prevention \& Rehabilitation (EACPR). Eur Heart J 2016;37:2315-81. 
371 doi:10.1093/eurheartj/ehw106.

372 


\section{Appendix - Paris-SDEC 2019 Investigators Listing (Supplementary File)}

374 Adnet F, Agostinucci JM, Aissaoui-Balanant N, Algalarrondo V, Alla F, Alonso C, Amara W, Annane D, Antoine 375 C, Aubry P, Azoulay E, Beganton F, Benhamou D, Billon C, Bougouin W, Boutet J, Bruel C, Bruneval P, Cariou 376 A, Carli P, Casalino E, Cerf C, Chaib A, Cholley B, Cohen Y, Combes A, Coulaud JM, Crahes M, Da Silva D, Das

377 V, Demoule A, Denjoy I, Deye N, Dhonneur G, Diehl JL, Dinanian S, Domanski L, Dreyfuss D, Duboc D,

378 Dubois-Rande JL, Dumas F, Empana JP, Extramiana F, Fartoukh M, Fieux F, Gabbas M, Gandjbakhch E, Geri G, 379 Guidet B, Halimi F, Henry P, Hidden Lucet F, Jabre P, Jacob L, Joseph L, Jost D, Journois D, Jouven X, Karam N, 380 Lacotte J, Lahlou-Laforet K, Lamhaut L, Lanceleur A, Langeron O, Lavergne T, Lecarpentier E, Leenhardt A, 381 Lellouche N, Lemiale V, Lemoine F, Linval F, Loeb T, Ludes B, Maltret A, Mansencal N, Mansouri N, Marijon E, 382 Marty J, Maury E, Maxime V, Megarbane B, Mekontso-Dessap A, Mira JP, Monnet X, Narayanan K, Ngoyi N, 383 Perier MC, Piot O, Pirracchio R, Plaisance P, Plu I, Raux M, Revaux F, Ricard JD, Richard C, Riou B, Roussin F, Santoli F, Schortgen F, Sharifzadehgan A, Sideris G, Spaulding C, Teboul JL, Timsit JF, Tourtier JP, Tuppin P, Ursat C, Varenne O, Vieillard-Baron A, Voicu S, Wahbi K, Waldmann V 
Figure 1: Study Flowchart between May 2011 and March 2016

389 Between May 2011 and March 2016, 18,306 out-of-hospital cardiac arrests, oh which 15,216 fulfilled the definition of SCA. Among them, 154 were sports-related.

Figure 2: Presumed Causes of Sudden Cardiac Arrest According to Occurrence During Sports

393 Coronary artery disease was the most frequent cause of SCA, with a higher prevalence in sports-related compared to non-sports related SCA. Non-cardiac causes were more frequent in non-sports related SCA. Supplementary Figure: Types of Sports Practiced at the time of Sudden Cardiac Arrest cases, 9.7\%) and fitness activities (13 cases, 8.4\%) 


\begin{tabular}{|c|c|c|c|c|}
\hline & $\mathrm{N}$ & $\begin{array}{c}\text { Non-sports } \\
\text { related SCA } \\
\mathrm{N}=13,246\end{array}$ & $\begin{array}{c}\text { Sports related } \\
\text { SCA } \\
\text { N=154 }\end{array}$ & $P$ value \\
\hline \multicolumn{5}{|l|}{ Demographic data } \\
\hline Age, years & 13,400 & $69.8[57.0-81.4]$ & $51.2[40.8-60.7]$ & $<0.001$ \\
\hline$\leq 40$ years & & $763(5.7)$ & $39(25.3)$ & $<0.001$ \\
\hline $40-60$ years & & $3284(24.8)$ & $73(47.4)$ & $<0.001$ \\
\hline$\geq 60$ years & & $9199(69.4)$ & $42(27.3)$ & $<0.001$ \\
\hline Male gender & 13,351 & $8455(64.1)$ & $148(96.1)$ & $<0.001$ \\
\hline \multicolumn{5}{|l|}{ Risk factors ${ }^{\dagger}$} \\
\hline Hypertension & 2,850 & $1111(40.5)$ & $28(25.9)$ & $0.751 *$ \\
\hline Dyslipidemia & 2,828 & $626(23.0)$ & $24(22.2)$ & $0.368^{*}$ \\
\hline Current smoker & 2,812 & $926(34.2)$ & $21(19.6)$ & $<0.001 *$ \\
\hline Diabetes mellitus & 2,846 & $575(21.0)$ & $6(5.6)$ & $0.006^{*}$ \\
\hline \multicolumn{5}{|l|}{ Medical history $^{+}$} \\
\hline Known heart disease & 2,865 & $932(33.9)$ & $19(16.5)$ & $0.014^{*}$ \\
\hline Know coronary artery disease & 2,820 & $512(18.9)$ & $8(7.0)$ & $0.015^{*}$ \\
\hline \multicolumn{5}{|c|}{ Characteristics of cardiac arrest } \\
\hline Public location & 13,298 & $2664(20.3)$ & $140(90.9)$ & $<0.001 *$ \\
\hline Witnessed status & 12,184 & & & $<0.001 *$ \\
\hline Non-witnessed & & $3520(29.3)$ & $7(4.6)$ & \\
\hline Witnessed without CPR & & $3872(32.2)$ & $25(16.3)$ & \\
\hline Witnessed with CPR & & $4639(38.6)$ & $121(79.1)$ & \\
\hline AED use & 9,202 & $130(1.4)$ & $21(14.7)$ & $<0.001^{*}$ \\
\hline EMS witnessed & 12,080 & $1369(11.5)$ & $16(10.8)$ & $0.887^{*}$ \\
\hline Call to EMS arrival $<9 \min$ & 12,809 & $5313(41.9)$ & $53(39.6)$ & $0.632 *$ \\
\hline Initial shockable rhythm & 11,354 & $2265(20.2)$ & $112(77.8)$ & $<0.001 *$ \\
\hline ECMO & 12,397 & $346(2.6)$ & $23(14.9)$ & $<0.001^{*}$ \\
\hline \multicolumn{5}{|l|}{ In hospital management $^{+}$} \\
\hline Coronary angiography & 2,858 & $1673(61.0)$ & $83(70.9)$ & $0.199 *$ \\
\hline Targeted temperature control & 2,773 & $1419(53.3)$ & $59(53.6)$ & $0.771 *$ \\
\hline \multicolumn{5}{|l|}{ Outcome } \\
\hline ROSC & 11,192 & $3242(29.4)$ & $95(62.9)$ & $<0.001^{*}$ \\
\hline Survival at hospital admission & 13,396 & $3084(23.3)$ & $122(79.7)$ & $<0.001^{*}$ \\
\hline Survival at hospital discharge & 13,003 & $658(5.1)$ & $58(39.7)$ & $<0.001 *$ \\
\hline Survival with CPC 1 or 2 & 12,974 & $600(4.7)$ & $49(35.3)$ & $<0.001^{*}$ \\
\hline
\end{tabular}

Values are median [25-75th percentile] or $\mathrm{n}$ patients (\%). Percentages were calculated on the basis of the total number of known events. SCA: Sudden Cardiac Arrest; CPR: CardioPulmonary

Resuscitation; AED: Automated External Defibrillator; EMS: Emergency Medical Service; ECMO: ExtraCorporeal Membrane Oxygenation; ROSC: Return of Spontaneous Circulation; CPC: Cerebral Performance Category.

${ }^{+}$Among survivors to hospital admission ( $\mathrm{N}=3084$, including 122 sport-related SCA).

*Adjusted for age and gender 
Table 2. Factors Associated with Survival at Hospital Discharge for Sudden Cardiac Arrest

\begin{tabular}{lcrrr}
\hline & \multicolumn{2}{c}{ Univariate analysis } & \multicolumn{2}{c}{ Multivariate Model } \\
\cline { 2 - 5 } & OR (95\% CI) & P value & OR (95\% CI) & P value \\
\hline Sports activity & $12.22(8.66-17.13)$ & $<0.001$ & $1.41(0.91-2.17)$ & 0.122 \\
Age, y & & & & \\
$\quad$ S40 & $4.20(3.27-5.34)$ & $<0.001$ & $2.88(2.09-3.94)$ & $<0.001$ \\
$\quad$ 41-59 & $3.37(2.86-3.97)$ & $<0.001$ & $1.98(1.62-2.43)$ & $<0.001$ \\
$\geq 60$ & 1.00 & & 1.00 & \\
Male gender & $2.00(1.68-2.41)$ & $<0.001$ & $0.90(0.71-1.14)$ & 0.3739 \\
Public location & $7.00(5.99-8.20)$ & $<0.001$ & $2.60(2.14-3.17)$ & $<0.001$ \\
Witnessed status & & & & \\
$\quad$ Non witnessed & 1.00 & & 1.00 & \\
$\quad$ Witness without CPR & $4.13(2.80-6.31)$ & $<0.001$ & $1.98(1.27-3.22)$ & 0.004 \\
$\quad$ Witness with CPR & $16.48(11.54-24.55)$ & $<0.001$ & $5.12(3.38-8.11)$ & $<0.001$ \\
AED use & $6.36(4.42-9.02)$ & $<0.001$ & & \\
EMS witnessed & $2.16(1.78-2.62)$ & $<0,001$ & & 0.003 \\
Call to EMS arrival $<9$ min & $1.34(1.14-1.57)$ & $<0.001$ & $1.33(1.10-1.61)$ & \\
Initial shockable rhythm & $29.43(23.82-36.72)$ & $<0.001$ & $16.13(12.71-20.68)$ & $<0.001$ \\
\hline
\end{tabular}


Table 3. Multivariate survival analysis

\begin{tabular}{lccc}
\hline & $\begin{array}{c}\text { Non-sports } \\
\text { N=12860 }\end{array}$ & $\begin{array}{l}\text { Sports } \\
\text { N=143 }\end{array}$ & P \\
\hline Survival, n (\%) & $\mathbf{6 5 8 ( 5 . 1 )}$ & $\mathbf{5 8 ( 3 9 . 7 )}$ & $<0.001$ \\
\hline OR, Model 0 & 1 & $\mathbf{1 2 . 2 2}(\mathbf{8 . 6 6 - 1 7 . 1 3 )}$ & $<0.001$ \\
OR, Model 1 & 1 & $7.19(5.02-10.22)$ & $<0.001$ \\
OR, Model 2 & 1 & $6.91(4.68-10.11)$ & $<0.001$ \\
OR, Model 3 & 1 & $3.23(2.17-4.75)$ & $<0.001$ \\
OR, Model 4 & 1 & $1.66(1.08-2.54)$ & 0.021 \\
OR, Model 5 & 1 & $1.41(0.91-2.17)$ & 0.122 \\
\hline
\end{tabular}

Model 0: Sports

Model 1: Sports + Age + Gender

Model 2: Sports + Age + Gender + Call to EMS arrival $<9$ min

Model 3: Sports + Age + Gender + Call to EMS arrival $<9$ min + Home location

Model 4: Sports + Age + Gender + Call to EMS arrival $<9$ min + Home location + Initial shockable rhythm

Model 5: Sports + Age + Gender + Call to EMS arrival $<9$ min + Home location + Initial shockable rhythm + Bystander initiated CPR 


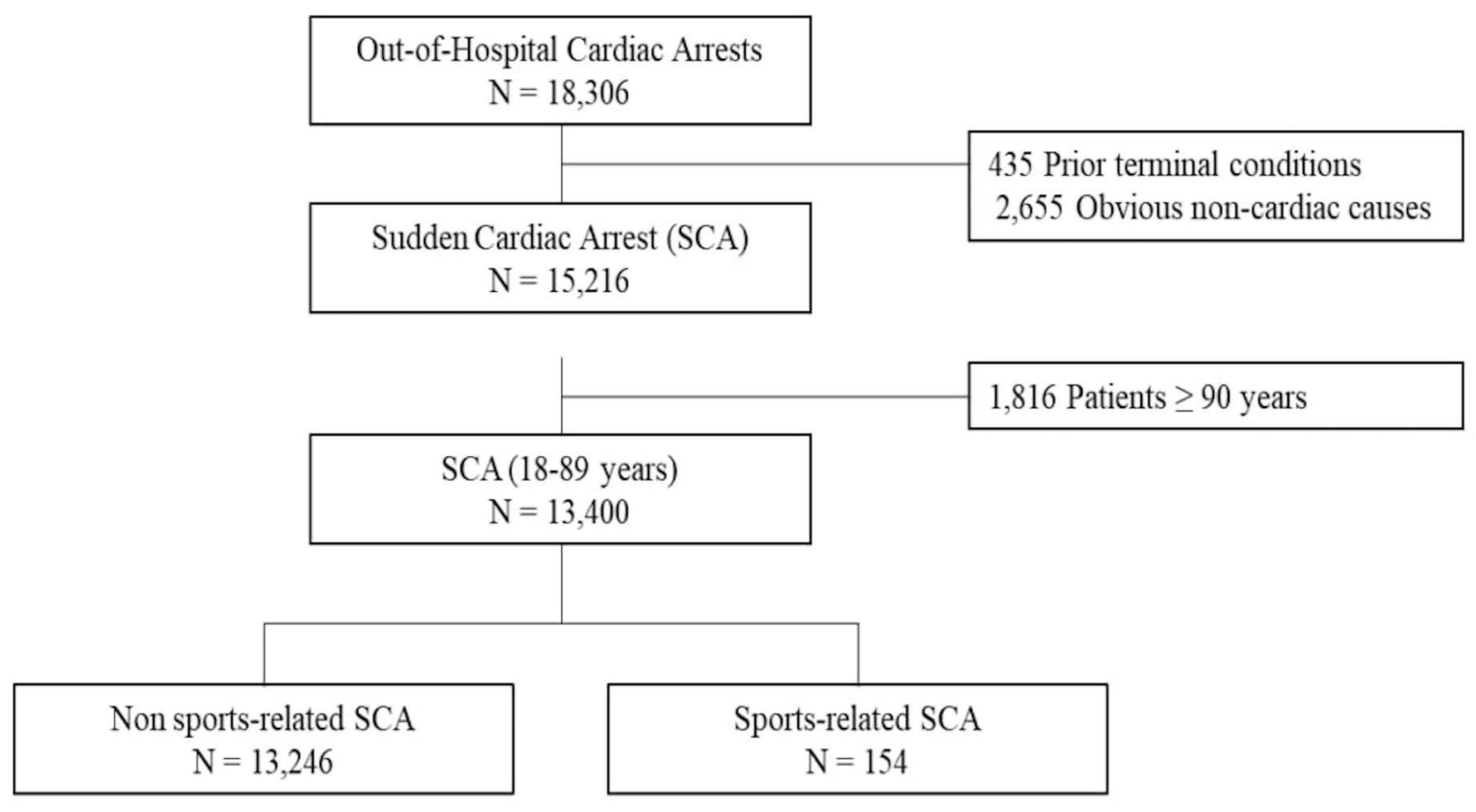


Non cardiac

Coronary artery disease

Channelopathy/Idiopathic VF

Dilated cardiomyopathy

Hypertrophic cardiomyopathy

Other coronary anomaly

- Sports related

non sports related

Valvular heart disease

Congenital heart disease

Other (cardiac) 


\section{Sports-Related Sudden Cardiac Arrest}

8-fold higher survival rate

\section{SCA}

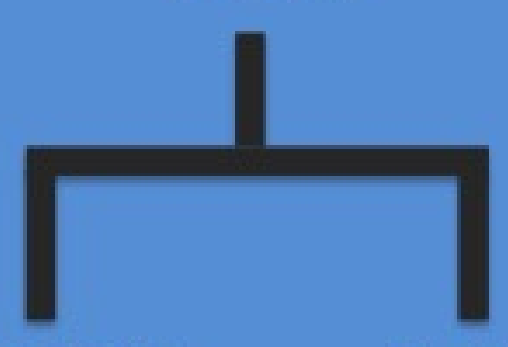

$39.7 \%$

SRSCA

$5.1 \%$ non-SRSCA
Better initial management

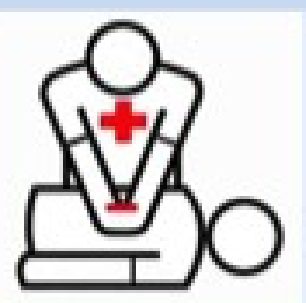

X2

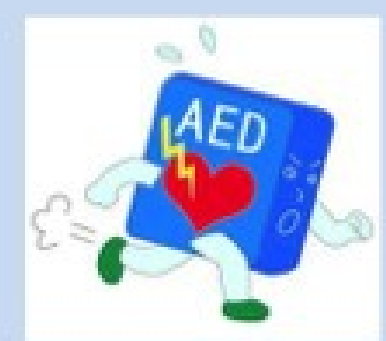

X10
BLS explains the better survival
Sports activity

OR 1.43, $\mathrm{P}=0.121$

(multivariate survival analysis) 